\title{
The Sexual Disgust Questionnaire; a Psychometric Study and a First Exploration in Patients with Sexual Dysfunctions
}

Citation for published version (APA):

van Overveld, M., de Jong, P. J. ., Peters, M. L., van Lankveld, J., Melles, R., \& ter Kuile, M. M. (2013). The Sexual Disgust Questionnaire; a Psychometric Study and a First Exploration in Patients with Sexual Dysfunctions. Journal of sexual medicine, 10(2), 396-407. https://doi.org/10.1111/j.17436109.2012.02979.x

Document status and date:

Published: 01/01/2013

DOI:

10.1111/j.1743-6109.2012.02979.x

Document Version:

Publisher's PDF, also known as Version of record

\section{Document license:}

Taverne

Please check the document version of this publication:

- A submitted manuscript is the version of the article upon submission and before peer-review. There can be important differences between the submitted version and the official published version of record.

People interested in the research are advised to contact the author for the final version of the publication, or visit the DOI to the publisher's website.

- The final author version and the galley proof are versions of the publication after peer review.

- The final published version features the final layout of the paper including the volume, issue and page numbers.

Link to publication

\footnotetext{
General rights rights.

- You may freely distribute the URL identifying the publication in the public portal. please follow below link for the End User Agreement:

www.umlib.nl/taverne-license

Take down policy

If you believe that this document breaches copyright please contact us at:

repository@maastrichtuniversity.nl

providing details and we will investigate your claim.
}

Copyright and moral rights for the publications made accessible in the public portal are retained by the authors and/or other copyright owners and it is a condition of accessing publications that users recognise and abide by the legal requirements associated with these

- Users may download and print one copy of any publication from the public portal for the purpose of private study or research.

- You may not further distribute the material or use it for any profit-making activity or commercial gain

If the publication is distributed under the terms of Article $25 \mathrm{fa}$ of the Dutch Copyright Act, indicated by the "Taverne" license above, 


\title{
The Sexual Disgust Questionnaire; a Psychometric Study and a First Exploration in Patients with Sexual Dysfunctions
}

\author{
Mark van Overveld, PhD, ${ }^{\star}$ Peter J. de Jong, Prof, ${ }^{\dagger}$ Madelon L. Peters, Prof, ${ }^{\ddagger}$ \\ Jacques van Lankveld, Prof, ${ }^{\S}$ Reinhilde Melles, Msc, ${ }^{\natural}$ and Moniek M. ter Kuile, $\mathrm{PhD}{ }^{* *}$ \\ *Erasmus University Rotterdam, Rotterdam School of Management, Rotterdam, the Netherlands; 'University of \\ Groningen, Department of Clinical Psychology, Groningen, the Netherlands; ${ }^{\ddagger}$ Maastricht University, Clinical \\ Psychological Science, Maastricht, the Netherlands; §Open University Heerlen, Department of Clinical Psychology, \\ Heerlen, the Netherlands; "Academic Hospital Maastricht, Department of Medical Psychology, Maastricht, the \\ Netherlands; ${ }^{\star \star}$ Leiden University Medical Center, Department of Gynaecology, Leiden, the Netherlands
}

DOI: $10.1111 / \mathrm{j} .1743-6109.2012 .02979 . x$

\section{A B S T R A C T}

Introduction. Disgust may be involved in sexual problems by disrupting sexual arousal and motivating avoidance of sexual intercourse. To test whether heightened disgust for sexual contaminants is related to sexual dysfunctions, the Sexual Disgust Questionnaire (SDQ) has recently been developed. Previous research showed that particularly women with vaginismus display a generally heightened dispositional disgust propensity and heightened disgust toward stimuli depicting sexual intercourse.

Aim. To determine the psychometric properties of the SDQ and test whether heightened disgust toward sexual stimuli is specific to vaginismus or can be observed in other sexual dysfunctions as well.

Methods. First, a large sample of undergraduates and university employees completed the SDQ $(\mathrm{N}=762)$ and several trait disgust indices. Next, women with vaginismus $(\mathrm{N}=39)$, dyspareunia $(\mathrm{N}=45)$, and men with erectile disorder $(\mathrm{N}=28)$ completed the SDQ and were compared to participants without sexual problems $(\mathrm{N}=70)$.

Main Outcome Measure. SDQ to index sexual disgust.

Results. The SDQ proved a valid and reliable index to establish disgust propensity for sexual stimuli. Supporting construct validity of the SDQ, sexual disgust correlated with established trait indices. Furthermore, sexual disgust and willingness to handle sexually contaminated stimuli were associated with sexual functioning in women, but not in men. Specifically women with vaginismus displayed heightened sexual disgust compared to women without sexual problems, while men with erectile disorders demonstrated a lower willingness to handle sexually contaminated stimuli compared to men without sexual problems.

Conclusions. The SDQ appears a valid and reliable measure of sexual disgust. The pattern of SDQ-scores across males and females with and without sexual dysfunctions corroborates earlier research suggesting that disgust appraisals are involved especially in vaginismus and supports the view that the difficulty with vaginal penetration experienced by women in vaginismus may partly be due to disgust-induced defensive reflexes that could disrupt sexual arousal. van Overveld M, de Jong PJ, Peters ML, van Lankveld J, Melles R, and ter Kuile MM. The Sexual Disgust Questionnaire; a psychometric study and a first exploration in patients with sexual dysfunctions. J Sex Med 2013;10:396-407.

Key Words. Disgust Propensity; Vaginismus; Dyspareunia; Erectile Disorder; Sexual Pain

\section{Introduction}

$M$ ost current psychological views of sexual behavior consider sexual dysfunction to be a consequence of a negative emotional reaction to erotic stimulation, which then becomes the focus of attention [1,2]. In line with this, there is considerable evidence that anxiety and (fear of) pain are involved in various sexual dysfunctions [3-5]. Recently, it has been argued that disgust may similarly play a role in the development of sexual dysfunctions [6]. 
Disgust involves strong negative affect [7] that may disrupt the development of sexual arousal. In addition, disgust may motivate withdrawal from particular sexual behaviors or avoidance of particular sex-related stimuli, which, in turn, may inadvertently influence the generation and/or maintenance of sexual arousal or lack thereof. In addition, disgust may give rise to strong defensive reflexes that are associated with its function to prevent hazardous pathogens entering the body [8]. These types of reflexes may also be elicited in sexual contexts and may-logically-have disrupting effects. For example, disgust may elicit retching during oral sex or kissing, or flinching of the pelvic floor muscles during attempts of sexual intercourse, which, in turn, may also disrupt sexual arousal. Thus, disgust could be associated with various sexual dysfunctions.

Therefore, the Sexual Disgust Questionnaire (SDQ) has recently been developed as an index of disgust propensity for sexual stimuli [9]. The SDQ was based on the Disgust Questionnaire (DQ) [10], which was originally designed to assess food rejection tendencies following trace contamination of these food items. The approach to assess disgust in the DQ is based on the central feature of disgusting stimuli, namely, that they readily transfer their offensive characteristics to other stimuli by brief contact [11]. The DQ consists of items such as: "Imagine your favorite soup. How much would you like to eat this soup after it has been stirred by a used fly swatter?" This questionnaire was modified to test the strength of individuals' tendencies to avoid physical contact with certain objects (e.g., a towel) after it has been in contact with certain sexual stimuli (e.g., sperm of the partner). Since contamination potency of particular sexual stimuli may vary as a function of the source of the potential contaminants, three possible sources were differentiated: the self, the partner, and an unknown person. In a preliminary study, the SDQ demonstrated good reliability for the total scale $(\alpha=0.90)$ while less than satisfactory levels were found for the three subscales representing the three sources of contamination ( $\alpha$ between 0.50-0.65) [9]. In support of the validity of the SDQ, higher levels of dispositional disgust propensity (as indexed by the Disgust Scale; DS [12]) were associated with lower willingness ratings (indexed by the SDQ) for contacting stimuli contaminated by an unknown person.

Given its strong defensive function to shield the individual from contamination, disgust could be involved in several sexual dysfunctions. For example, in problems with sexual penetration like vaginismus (i.e., a persistent or recurrent difficulty to allow vaginal entry of the penis, a finger, and/or any object, despite the woman's expressed wish to do so) [13], or in complaints related to the generation of sexual arousal (e.g., erectile disorder). The unique contribution of disgust in vaginismus may lie in the strong defensive function of disgust which could be associated with the inability to experience vaginal penetration. One of the defining behavioral features of vaginismus is the inability to engage in intercourse, which is typically accompanied by strong defensive reactions [13]. One interpretation of such defensive behaviors is that they may be the result of disgust-related defensive reflexes. Additionally, since feelings of disgust may logically interfere with the generation and/or maintenance of sexual arousal, heightened disgust for sexual stimuli might well be involved in sexual arousal disorders such as male erectile disorder. Thus, a logical assumption is then that disgust is not necessarily restricted to sexual functioning in women. By producing penile flaccidity, disgust could protect a man from penetrating a woman suffering from contagious genital disease that accompanies some sexually transmitted diseases (e.g., the " fishy" smell in case of chlamydia or bacterial vaginosis).

So far, research has mainly focused on the role of disgust in lifelong vaginismus [9,14]. In support of the view that disgust may indeed be involved in vaginismus, women with lifelong vaginismus reported heightened levels of dispositional disgust propensity (i.e., individual's tendency to experience disgust more readily) compared to women without sexual dysfunctions [9]. However, the finding that women with vaginismus displayed heightened levels of disgust propensity may not indicate that disgust is generally involved in sexual dysfunctions.

In support of the idea that disgust could be involved in sexual (dys)functions, via affecting sexual arousal levels, women with vaginismus or dyspareunia frequently report disturbances in sexual arousal during intercourse [15-17]. However, women with vaginismus did not demonstrate lower willingness ratings on the SDQ compared to women without sexual dysfunctions [9]. One testable explanation for the absence of a difference in SDQ scores between women with and without a sexual dysfunction might be that "willingness" ratings were used rather than directly asking for subjective disgust. It may be questioned 
whether willingness ratings are a proper candidate for investigating the potential to evoke disgust responses in sexual dysfunctions.

Thus, several issues require further consideration. First, the original SDQ might have lacked sufficient sensitivity to detect relevant differences in sexual disgust since the willingness to touch stimuli may also be influenced by factors other than disgust (e.g., culture, religion). In addition, it might be that the current SDQ lacked adequate psychometric qualities in terms of subscale reliability and factor structure, which could also contribute to its insensitivity as a measure of individual differences in disgust propensity for sexual stimuli. It seems, therefore, important to supplement the willingness items of the original SDQ with questions directly asking for participants' feelings of disgust for these contaminants. This would allow to establish whether the willingness ratings to handle sexual contaminants are in fact associated with levels of disgust. Second, it seems important to evaluate the psychometric properties of the SDQ in terms of subscale reliability and factor structure, and to test whether the hypothesized three factors distinction (i.e., self, partner, unknown person) is appropriate. Third, it seems important to investigate whether disgust for sexual stimuli might be specifically involved in vaginismus or can be best considered as a more general feature of sexual dysfunctions. Although studies have mainly focused on the role of disgust in vaginismus compared to dyspareunia $[14,18]$, this strict demarcation between these disorders is not without debate and there is a significant overlap of dyspareunia with vaginismus in terms of symptoms [19-21]. However, several differences may be observed. Compared to women with dyspareunia or without sexual problems, women with vaginismus seem to endorse stronger conservative sexual moral standards [14], display more negative deliberate appraisals of sexual intercourse stimuli $[18,22]$, demonstrate harm-avoidant personality traits [23], and tend to have more negative image of their body [17]. Most important with regard to the phenomenological level, women with lifelong vaginismus are characterized by a consistent inability for vaginal penetration. Consequently, they have never had sexual intercourse, whereas in women with dyspareunia, sexual intercourse is still possible [24]. While pain tends to be observed in both women with vaginismus and dyspareunia upon penetration attempts, a disgust-related defensive reaction to sexual stimuli could be specific to women with vaginismus and thus present a defining feature on the basis of which women with dyspareunia could be distinguished from women with vaginismus.

Accordingly, the first aim of this study was to evaluate the psychometric characteristics of the current SDQ. Second, associations were explored between (sexual) arousal and scores on the current version of the SDQ in individuals without sexual complaints. The first part of the study relied on a large non-clinical group of women and men without sexual problems. Both genders were included to explore whether the levels of sexual disgust were similar for men and women with and without sexual problems. The second part of the study focused on treatment-seeking individuals and tested whether sexual disgust might be involved in women with sexual problems. To follow-up previous findings [9], again a group of women was selected who were suffering from lifelong vaginismus. For the purpose of this paper, the term vaginismus will be used in lieu of lifelong vaginismus. To examine whether heightened levels of disgust toward sexual stimuli would be specific to women with lifelong vaginismus, two other clinical groups were also included. One group consisted of women suffering from superficial dyspareunia (i.e., pain during sexual activities associated with vaginal penetration, with the vulvar vestibule as main focal point for pain). The other clinical group was comprised of men with erectile disorder (i.e., inability to achieve or maintain an erection during sexual intercourse) [24]. Male erectile disorder was selected as these are among the most prevalent sexual dysfunctions in men [25]. The inclusion of erectile disorder has the additional benefit that it allows to explore whether there might be gender differences in the relevance of sexual disgust for the development of sexual dysfunctions (e.g., [26]).

\section{Aims}

The current study investigated the psychometric properties of the SDQ and examined whether sexual disgust is specifically elevated in a clinical sample of women with vaginismus or also in individuals with other sexual dysfunctions (dyspareunia, erectile disorder). More specifically, we examined whether the SDQ can be considered as a valid and reliable index of sexual disgust, and tested whether the levels of disgust for stimuli contaminated with sexual byproducts are associated both with vaginismus and other sexual complaints (i.e., dyspareunia and erectile disorder). 


\section{Methods}

\section{Participants}

This study consisted of two parts: a study on the psychometric properties of the SDQ, and a clinical study to examine the role of sexual disgust in clinical groups with sexual dysfunctions. The first part relied on a large sample of students and university employees from Maastricht University $(\mathrm{N}=762$; $67.5 \%$ women) who were recruited in two waves. The mean age of participants was 27.93 years $(S D=10.15)$.

The participants of the clinical study were recruited at three Dutch sexology centers: the Center of Sexology at the Maastricht University Medical Center, the outpatient clinic for psychosomatic gynecology and sexology of Leiden University Medical Center, and ProPsy in Sittard (only men were recruited at ProPsy). For inclusion in a clinical group, general inclusion criteria included the following: heterosexual orientation, aged over 18 years, in a heterosexual relationship for at least 3 months, and sexual complaints caused considerable distress in the individual.

Women with vaginismus and dyspareunia underwent a structured interview by a senior sexologist and each woman was questioned about her medical history and current somatic complaints by a gynecologist using a standardized form. Special attention was paid to possible signs of a co-occurring vaginal infection and/or problems with urination and defecation. The physical examination of women suffering from vaginismus consisted of a thorough examination of the external genitals, the vaginal vestibule and the hymenal orifice to rule out congenital hymenal abnormalities like a hymen semilunaris altus. The touch test with a moistened cotton wool swab was also performed to assess signs of provoked vestibulodynia (PVD). In women with dyspareunia, a similar examination was performed. A bacterial culture of the vaginal discharge was taken if appropriate. Women suffering with vaginismus were explicitly informed that the physical examination procedure would be limited to external examination of the vulva (external genitalia). Although some women with lifelong vaginismus were very anxious, none refused the investigation and an external examination was possible for all of them.

For the vaginismus group, women were required to have a diagnosis of lifelong vaginismus; thus, women who, despite multiple attempts, were never able to experience vaginal intercourse. A woman was excluded when she reported to have had vaginal penetration with thrusting or vaginal penetration involving the entire length of the penis at any time (cf. [27]).

For the dyspareunia group (acquired and lifelong dyspareunia), women were required to: experience pain during in more than $50 \%$ of intercourse (attempts) for at least the past 6 months; pain during intercourse is the primary complaint and pain is limited to intercourse and other activities involving vestibular pressure. In the dyspareunia group, women reported that they had full intercourse at least at one attempt during the last 6 months. Most of these women had intercourse on a regular basis (weekly).

For male erectile disorder (acquired and lifelong type), the following inclusion criteria were used: problems with maintaining or obtaining an erection in at least $50 \%$ of intercourse attempts, lasting at least 6 months, and which is not better accounted for by a medical condition or substance use (e.g., medication). The men with an erectile disorder did not receive a physical examination.

This led to a group of women with vaginismus $(\mathrm{N}=39)$ with a mean age of $31.46(\mathrm{SD}=7.55$; range 20-51 years), dyspareunia $(\mathrm{N}=45)$ with a mean age of 28.94 ( $\mathrm{SD}=7.67$; range $19-57)$, and men with erectile disorder $(\mathrm{N}=28)$ with a mean age of 53.29 ( $\mathrm{SD}=11.04$; range 29-73). To acquire a representative control group for the clinical groups, participants in the clinical groups were matched to participants from the non-clinical study.

Control participants were selected from the non-clinical research population participating in the psychometric study. To ensure that they did not score within the clinical range, standard cutoff criteria for healthy functioning for women (FSFI > 26.55) and men (IIEF > 25) were used. For each person in the clinical groups, the age of the match was allowed to deviate with a maximum of 2 years. Next, for vaginismus and dyspareunia, a combined control group was randomly selected from the pool of matched persons for the mean number of women with vaginismus and dyspareunia $(\mathrm{N}=42)$, with a mean age of 30 years $(S D=8.11$; range $19-57)$. For men with erectile disorder, a control group of 28 men was randomly selected with a mean age of 52 years $(\mathrm{SD}=8.90$; range 29-64).

\section{Measures}

SDQ; [9]

The SDQ assesses participants' willingness to handle contaminants in the sexual domain, which 
was proposed to indicate an individual's disgust propensity toward sexually contaminated items (SDQ-W). For the current study, a disgustingness scale was added (SDQ-D) to assess how disgusted participants imagined to be if they were to handle the same nine items (for full SDQ, see [9]). In both scales, the items cover three types of contaminants for which subscales may be derived: Self, Partner, and Unknown. On a scale from 0 (= certainly not willing) to 8 (= certainly willing; range $0-72$ for the total score, $0-24$ for the subscales), participants rate their willingness (SDQ-W) to handle nine contaminated items. Higher scores on SDQ-W indicate higher levels of willingness to handle sexually contaminated items, higher scores on SDQ-D indicate higher levels of disgust toward those items.

\section{Disgust Propensity and Sensitivity Scale-Revised (DPSS-R; [28])}

This index measures disgust propensity (i.e., a tendency to experience disgust more readily) and sensitivity (i.e., a tendency to consider experiencing disgust negatively). Two subscales on disgust propensity (DPSS-RP) and disgust sensitivity (DPSS-RS) can be obtained. Participants rate 12 propositions on the frequency of experiencing bodily sensations on a scale from 1 (= never) to 5 (= always; range: $12-60$ and $6-30$ for each subscale). Higher scores indicate higher levels of disgust propensity and disgust sensitivity. The DPSS-R demonstrated good construct validity $[28,29]$ as well as predictive validity [29]. Also in the current sample, internal consistency was satisfactory for both disgust propensity $(\alpha=0.81)$ and sensitivity $(\alpha=0.75)$.

\section{DS; [12]}

The 32-item DS measures disgust propensity for various disgust elicitors. On the first part, participants rate their agreement with 16 propositions using a dichotomous scoring format $(0=$ false, $1=$ true). On the second part, participants indicate how disgusted they are by 16 objects $(0=$ not disgusting at all to $2=$ extremely disgusting). Although the 32-item version was administered, in line with recent recommendations [30], only 25 items were used for the analyses. Higher total scores (range 0-25) indicate higher disgust propensity levels. The DS has demonstrated good construct validity and discriminant validity for various disgust types (e.g., [31]). Internal consistency is high for the total score $(\alpha=0.84$ [12]; in the current study $\alpha=0.78$ ).
Female Sexual Functioning Index (FSFI; [32])

The FSFI is a brief, self-report index measuring sexual function in women. In this study, the subscales on subjective arousal (AR) and lubrication ( $\mathrm{LU}$; as a proxy of physiological arousal) were used, as well as the total score as a global indication of sexual function. Participants complete 19 items on sexual feelings and responses of the past 4 weeks using various Likert-type scoring formats. Higher scores indicate better sexual function (range 2-36). Construct validity is good [32] as well as discriminant, convergent, divergent, and predictive validity [33]. Internal consistency for the total score is high in volunteers from the general population (0.95 [32]; 0.97 current study) and in women with sexual arousal disorder (0.93) [32]. Internal consistency is also high for the subscales (Current study: AR: 0.95).

\section{International Index of Erectile Function (IIEF; [34])}

The IIEF measures participants' erectile function and its effect on their sex life over the past 4 weeks. The Erectile Function (EF) subscale was used as a proxy for sexual arousal, and the total score as a global index of erectile function. The IIEF consists of 15 items and uses various Likert-type scoring formats. Eight items are rated on a 5-point Likert scale (1-5) while seven items included a "does not apply" option, thus, a 6-point Likert-scale (0-5). Higher scores reflect higher levels of erectile function (range 8-75). It has demonstrated good convergent, divergent, and discriminant validity [35]. Internal consistency for the total score is high in various samples $(\alpha=0.73-0.99$ [35]; in the current study $\alpha=0.96$ for the total score, EF: $\alpha=0.92$ ).

\section{Procedure}

During 2 years, a large questionnaire study was conducted at Maastricht University. In both recruitment waves for these studies, participants were recruited via advertisements in the university paper and posters throughout the university buildings. Participants were told the study was about sex and sexual acts and only served scientific purposes. In the first wave (in the first year), only the current version of the SDQ was administered $(\mathrm{N}=458)$. During the second wave, participants additionally completed the DPSS-R, DS and, depending on gender, the FSFI or IIEF $(\mathrm{N}=304)$. These last two questionnaires were administered to verify that the control groups were in the normal range of sexual functioning. Participants were allowed to complete the questionnaire at home (after making 
strict appointments for returning the questionnaire) or were given the opportunity to complete it in small groups in a conference room at the department. On behalf of another study, several other questionnaires on emotion were administered. Participants were informed that they could win 50 euros via a lottery for their participation. However, it was emphasized that completing the SDQ (the last questionnaire in the package) was strictly optional and that refusing to complete the SDQ did not affect their chances to enter in that lottery.

The three clinical groups were recruited at the three sexology centers. All participants in the clinical groups met the inclusion criteria for vaginismus, dyspareunia, or erectile disorder, and were treatment-seeking at the time of the study. They were invited for the current study before treatment was started and were told the study was about sex and sexual acts and only served scientific purposes. All women with vaginismus and dyspareunia received the current SDQ at the end of the diagnostic procedure and were allowed to complete the questionnaire at home. Approximately 10-20\% refused participation in the present study. Men with erectile disorder received the SDQ during the intake procedure, as part of a larger package of questionnaires that the clinical groups are generally asked to complete upon their first appointment at the sexology center. They were allowed to complete the questionnaires at home, and were encouraged to bring the package back with them on their next appointment. Approximately $25 \%$ of the men refused to take part in the study and did not return the package. Participation was strictly voluntary for all clinical groups. They did not enter the lottery. Finally, the research has been conducted following APA ethical standards and was approved by the ethical committee at Maastricht University.

\section{Data Analyses}

Using the Statistical Package for Social Sciences (SPSS version 17.0; SPSS Inc., Chicago, IL, USA), missing data were computed using regression analyses following recommendations by Schafer and Graham [36], unless more than $10 \%$ of values was missing $(\mathrm{N}=4)$. If more than $10 \%$ was missing, the data were removed from the analyses. Preliminary analyses on the SDQ in the non-clinical sample consisted of item analyses for normality and linearity. Further analyses were performed on an item-by-item basis to retain items with adequate psychometric properties. Items in which more than $65 \%$ of participants used only the first response alternative and items that demonstrated low correlations with all other items $(r \leq 0.35)$ were excluded from factor analyses (for SDQ-W: 1, 3, 6; for SDQ-D: 1, 3, 6). For items with skewed distributions $(\leq-1$ or $\geq 1), \log$ transformations were applied (for SDQ-W: 5, 8, 9; for SDQ-D: 2, 4, 7). Since three of the six Self- and Partner-items from both the willingness and disgustingness scale were deleted, the remaining items were collapsed into a new subscale (familiar sources of contamination). Next, in the non-clinical sample, confirmatory factor analyses (CFA) compared a two-factor model (Familiar vs. Unknown) to a one-factor model. CFA was performed with LISREL 8.54 using weighted least-squares estimation. Latent variables were free to correlate, and secondary item-loadings were not allowed. Separate analyses were performed for willingness and disgustingness.

A series of bivariate correlations were used to examine in the non-clinical sample whether the willingness to approach sexually contaminated stimuli (SDQ-W) was associated with disgust of these stimuli (SDQ-D). Only correlation coefficients with at least a medium effect size $(r>0.30)$ were considered interesting. To establish convergent validity of the SDQ, correlations with DPSS-R and DS were examined as well as with indices on sexual functioning (FSFI or IIEF) in the non-clinical sample. Next, to compare between clinical groups and control participants without sexual problems, SDQ-subscales were constructed in the clinical sample (and their matched controls) in line with the findings from the CFA (see Appendix for the current version of the SDQ). To evaluate whether the clinical groups and their respective control groups responded differently to the questionnaires, their scores were subjected to a series of one-way Multivariate Analyses of Variance (MANOVA). As women generally report higher levels of disgust propensity than men (e.g., [26]), the analyses were performed separately for men and women. Where appropriate, effect sizes were calculated (eta-squared; $\eta^{2}$ ). Generally, effect sizes of 0.01 are considered small effects, 0.06 medium effects, and 0.14 or higher as large effects [37].

\section{Results}

\section{Factor Analyses}

Model fit was assessed using absolute and incremental fit indices. The chi-square test $\left(\chi^{2} /\right.$ d.f.) is an absolute fit index. Generally, a ratio below 3 is considered acceptable. Table 1 shows that this ratio was poor for the one-factor models of SDQ-W and 
Table 1 Confirmatory factor analyses for willingness (SDQ-W) and disgustingness (SDQ-D) in the non-clinical sample

\begin{tabular}{|c|c|c|c|c|c|c|c|c|}
\hline & $\chi^{2}$ & d.f. & $\chi^{2} /$ d.f. & $\mathrm{AIC}$ & $\mathrm{CFI}$ & TLI & RMSEA & ECVI \\
\hline \multicolumn{9}{|l|}{ One factor } \\
\hline Willingness & 237.27 & 9 & 26.36 & 296.28 & 0.87 & 0.78 & 0.19 & 0.38 \\
\hline Disgust & 505.12 & 9 & 56.12 & 476.73 & 0.72 & 0.55 & 0.25 & 0.63 \\
\hline \multicolumn{9}{|l|}{ Two factors } \\
\hline Willingness & 53.11 & 8 & 6.63 & 77.53 & 0.97 & 0.95 & 0.08 & 0.10 \\
\hline Disgust & 33.00 & 8 & 4.13 & 57.78 & 0.98 & 0.97 & 0.06 & 0.08 \\
\hline Valid N & & & & & & & & 761 \\
\hline
\end{tabular}

Abbreviations: SDQ-W = Sexual Disgust Questionnaire-Willingness; SDQ-D = Sexual Disgust Questionnaire-Distgustingness; d.f. = degrees of freedom; $\mathrm{AIC}=$ Akaike Information Criterion; CFI = Comparative Fit Index; TLI = Tucker-Lewis Index; RMSEA = Root Mean Square Error of Approximation; ECVI = Expected Cross-Validation Index

SDQ-D. The two-factor model performed markedly better although the ratio was still above 3 .

To assess incremental fit indices, cut-off criteria for good fit by $\mathrm{Hu}$ and Bentler [38] were used: Comparative Fit Index $(\mathrm{CFI})>0.95$, Tucker-Lewis Index $(\mathrm{TLI})>0.95$, and Root Mean Square Error of Approximation (RMSEA) $<0.06$. According to these criteria, the one-factor models for SDQ-W and SDQ-D did not fit well, while model fit was acceptable for the two-factor models.

Next, a likelihood ratio test was used to evaluate whether the two-factor structure has additional value compared to a one-factor model by comparing the difference in chi-square values of the models. The two-factor models fit the data significantly better than the one-factor models $(P<0.001)$. Additionally, the Expected CrossValidation Index (ECVI) provides a descriptive evaluation of competing models. The model with the lowest value fits best. The ECVI was lowest for the two-factor models. A two-factor solution appeared superior to a one-factor solution.

Thus, the CFA supports the internal validity of a SDQ with the subscales willingness_familiar (items 1, 2, 4); willingness_unknown (items 3, 5, 6); disgustingness_familiar (items 7, 8, 10); and disgustingness_unknown (items 9, 11, 12) (see Appendix). In line with the findings from the CFA, the subscales for familiar and unknown were constructed for the SDQ-W and SDQ-D. Table 2 presents descriptive statistics and internal consistencies of the subscales. In accordance with criteria by Nunnally [39], internal consistency was good for both the total scales of SDQ-W $(\alpha=0.75)$ and SDQ-D $(\alpha=0.76)$, and acceptable for the subscales of SDQ-W $(\alpha=0.59-0.82)$ and SDQ-D $(\alpha=0.59-0.81)$ in the non-clinical research population. Also, in the clinical sample, internal consistency was good for the total scale of SDQ-W $(\alpha=0.75)$ and SDQ-D $(\alpha=0.74)$, while lower for the subscales of SDQ-W $(\alpha=0.49-0.82)$ and SDQ-D $(\alpha=0.59-0.83)$.

\section{Intercorrelations of SDQ Subscales and Correlations} with General Disgust Indices

Bivariate correlations were computed between the subscales of the SDQ for the entire sample. There were only moderate correlations between the scales for familiar and unknown $(r=0.41$ for SDQ-W, $r=0.38$ for SDQ-D). This supports the view that the two scales are measuring related but not identical constructs. Consistent with the assumption that the motivation to approach sexual stimuli is strongly associated with disgust, Table 3 shows that correlations between SDQ-W and SDQ-D were high.

\section{Correlations of SDQ Subscales with Sexual Functioning}

To determine whether lower willingness (SDQ-W) and higher disgustingness (SDQ-D) were associated with lower levels of sexual arousal in the non-clinical population, bivariate correlations were calculated between either the subjective arousal scale (AR) and the physiological arousal scale (LU) of the FSFI $(\mathrm{N}=186)$ or the erectile function (EF) of the IIEF $(\mathrm{N}=109)$ with both subscales of the SDQ. In women, higher levels of

Table 2 Means, standard deviations, range and internal consistency of the SDQ-W and SDQ-D scales in the non-clinical sample

\begin{tabular}{lrll}
\hline & Means & $\begin{array}{l}\text { Actual } \\
\text { range }\end{array}$ & $\begin{array}{l}\text { Cronbach's } \\
\text { alpha }\end{array}$ \\
\hline SDQ-W & & & \\
Familiar & $10.37(6.18)$ & $0-24$ & 0.82 \\
Unknown & $7.23(4.86)$ & $0-24$ & 0.59 \\
Total & $17.60(9.30)$ & $0-46$ & 0.75 \\
SDQ-D & & & \\
Familiar & $9.16(5.80)$ & $0-24$ & 0.81 \\
Unknown & $15.12(5.15)$ & $0-24$ & 0.59 \\
Total & $24.28(9.15)$ & $0-48$ & 0.76 \\
Valid N & & & 761 \\
\hline
\end{tabular}

Note: Standard deviations are presented in parentheses.

Abbreviations: SDQ-W = Sexual Disgust Questionnaire-Willingness; SDQ$\mathrm{D}=$ Sexual Disgust Questionnaire-Disgustingness 
Table 3 Bivariate correlations between SDQ-subscales in the non-clinical population and in a subsample of those participants who also completed general disgust indices (DPSS-R, DS)

\begin{tabular}{|c|c|c|c|c|}
\hline \multirow[b]{2}{*}{ Indices } & \multicolumn{2}{|l|}{ SDQ-W } & \multicolumn{2}{|l|}{ SDQ-D } \\
\hline & Familiar & Unknown & Familiar & Unknown \\
\hline \multicolumn{5}{|l|}{ SDQ-W } \\
\hline \multicolumn{5}{|l|}{ Familiar } \\
\hline Unknown & $0.41^{\star *}$ & & & \\
\hline Total & $0.88^{\star *}$ & $0.80^{\star \star}$ & & \\
\hline \multicolumn{5}{|l|}{ SDQ-D } \\
\hline Familiar & $-0.69^{\star *}$ & $-0.28^{\star \star}$ & & \\
\hline Unknown & $-0.33^{\star \star}$ & $-0.57^{\star \star}$ & $0.40^{\star *}$ & \\
\hline Total & $-0.63^{\star *}$ & $-0.49^{\star *}$ & $0.86^{\star *}$ & $0.81^{* *}$ \\
\hline Valid N & & & & 762 \\
\hline \multicolumn{5}{|c|}{ Disgust propensity indices } \\
\hline DPSS-RP $(\alpha=0.81)$ & 0.00 & -0.09 & 0.08 & $0.22^{\star \star}$ \\
\hline DPSS-RS $(\alpha=0.75)$ & -0.04 & -0.07 & 0.08 & $0.13^{\star}$ \\
\hline DS total $(\alpha=0.78)$ & $-0.37^{\star \star}$ & $-0.35^{\star \star}$ & $0.34^{* *}$ & $0.43^{\star *}$ \\
\hline Valid N & & & & 304 \\
\hline
\end{tabular}

willingness to approach stimuli contaminated by familiar sources (SDQ-W) were significantly negatively associated with levels of $\mathrm{AR}(r=0.32$; $P<0.01)$ and $\mathrm{LU}(r=0.31 ; P<0.01)$. Additionally, higher levels of AR and LU were associated with significantly lower levels of disgustingness (SDQ-D) (both $r=-0.32 ; P<0.01$ ) for familiar sources of contamination. For men, no significant correlations were observed between levels of willingness (SDQ-W) or disgustingness (SDQ-D) and the EF-scale (all $r<0.15$ ).

\section{Group Differences in SDQ-Willingness}

For women, a 2 (Source: familiar, unknown) $\times 3$ (Group: Vaginismus, Dyspareunia, Controls) MANOVA was performed. This revealed neither a significant Source $\times$ Group interaction $(F(1,123)=$ $\left.0.75, P=0.48, \eta^{2}=0.01\right)$ nor a main effect of Group $\left(F(1,123)=0.61, P=0.55, \eta^{2}=0.01\right)$. This indicates that women with vaginismus or dyspareunia were not less willing to expose themselves to sexual stimuli compared to control participants. For men, a 2 (Source: familiar, unknown) $\times 2$ (Group: Male Erectile Disorder, Control group) MANOVA was performed. This showed a significant Source $\times$ Group interaction $\left(F(1,54)=6.51, \quad P=0.01, \quad \eta^{2}=0.08\right)$. Specific contrasts using independent sample t-tests showed that men with erectile disorder scored lower on willingness toward familiar-stimuli than control participants $\left(t(54)=2.01, P=0.04 ; \eta^{2}=0.08\right)$.

Means and standard deviations for all questionnaires are presented in Table 4.

\section{Group Differences in SDQ-Disgustingness}

For women, a 2 (Source: familiar, unknown) $\times 3$ (Group: Vaginismus, Dyspareunia, Control group) MANOVA was performed. A significant Source $\times$ Group interaction term $(F(2,123)=3.71, P=0.03$, $\eta^{2}=0.03$ ) was found. A series of contrasting independent sample t-tests were then performed. As expected, overall, participants scored higher on SDQ-unknown compared to SDQ-familiar $\left(F(1,123)=95.15, P<0.01, \eta^{2}=0.42\right)$. Yet, only women with vaginismus scored significantly higher on SDQ-familiar compared to participants with dyspareunia $\left(t(82)=2.49, P=0.02 ; \eta^{2}=0.07\right)$ and control participants without sexual problems $\left(t(79)=1.99, P=0.05 ; \eta^{2}=0.05\right)$. In men, a 2 (Source: familiar, unknown) $\times 2$ (Group: Erection Disorder, Control group) MANOVA wasperformed and revealed no significant interactions $\left(F(1,54)=2.42, P=0.13, \eta^{2}=0.03\right)$.

\section{Discussion}

The main findings of the present study were: (i) CFA supported a two-factor structure of the

Table 4 Means, standard deviations of all questionnaires in the clinical sample (individuals with vaginismus, dyspareunia, erectile disorder and their age-matched participants from the non-clinical sample)

\begin{tabular}{|c|c|c|c|c|c|}
\hline Indices & $\begin{array}{l}\text { Vaginismus } \\
(\mathrm{N}=39)\end{array}$ & $\begin{array}{l}\text { Dyspareunia } \\
(\mathrm{N}=45)\end{array}$ & $\begin{array}{l}\text { Controls } \\
(\mathrm{N}=42)\end{array}$ & $\mathrm{ED}(\mathrm{N}=28)$ & $\begin{array}{l}\text { Controls } \\
(\mathrm{N}=28)\end{array}$ \\
\hline \multicolumn{6}{|l|}{ SDQ-W } \\
\hline Familiar & $7.95(5.40)$ & $9.53(6.08)$ & $9.48(6.77)$ & $9.32(7.62)^{*} \eta 2=0.08$ & $13.57(7.54)$ \\
\hline Unknown & $6.33(4.40)$ & $6.29(4.58)$ & $6.90(4.50)$ & $7.25(4.51)$ & $7.18(5.20)$ \\
\hline $\begin{array}{l}\text { Total } \\
\text { SDQ-D }\end{array}$ & $14.28(7.95)$ & $15.82(8.80)$ & $16.38(9.65)$ & $16.57(10.62)$ & $20.75(11.47)$ \\
\hline Familiar & $12.77(6.11)^{\star} \eta^{2}=0.05$ & $9.49(5.93)$ & $10.90(6.50)$ & $10.29(7.65)$ & $6.89(6.62)$ \\
\hline Unknown & $16.36(4.23)$ & $16.96(5.61)$ & $16.93(4.10)$ & $14.79(4.57)$ & $14.50(6.21)$ \\
\hline Total & $29.12(5.58)$ & 26.44 (9.13) & 27.83 (8.82) & 25.07 (11.21) & $21.39(9.29)$ \\
\hline
\end{tabular}

${ }^{\star} P<0.05,{ }^{\star \star} P<0.01$

Abbreviations: $\mathrm{SDQ}=$ Sexual Disgust Questionnaire; $\mathrm{W}=$ Willingness; $\mathrm{D}=$ Disgustingness; $\mathrm{ED}=$ Erectile Disorder 
current version of the SDQ; (ii) the two-factor model demonstrated moderate internal consistency and good convergent validity; (iii) women with vaginismus reported higher levels of disgust for stimuli contaminated with sexual byproducts related to familiar persons than women with dyspareunia and women without sexual problems; and (iv) men with erectile disorder demonstrated lower willingness to approach stimuli contaminated with sexual byproducts related to familiar persons than men without sexual problems.

Originally, the SDQ was designed to measure three sources of contamination: self, partner, and unknown persons [9]. Yet, the current analyses revealed that several items did not demonstrate adequate psychometric properties. These items were removed from the current version of the SDQ. Next, CFA did not support the previously suggested three factor structure [9] and the remaining items for Self and Partner loaded on one factor. CFA revealed that the resulting twofactor structure (familiar/unknown) fitted the data well and significantly better than a one-factor baseline model. Moreover, the internal consistency of the subscales based on the two factor models were low to moderate and the resulting subscales (SDQ-W, SDQ-D) correlated meaningfully with an established trait disgust propensity index (DS). Further attesting to the validity of the current SDQ, negative correlations were observed between disgustingness (SDQ-D) and willingness (SDQ-W). Thus, participants' reported willingness to handle particular sexually contaminated stimuli was associated with the intensity of disgust they reported when asked to imagine a situation where they would actually have close physical contact with these stimuli. Yet, although both SDQ-scales were associated, they were certainly not equivalent, since only $52 \%$ of the variance in willingness-scores (familiar-source) was shared by the variance in disgustingness. This underlines the relevance of adding the disgustingness ratings to the original SDQ. Together, the psychometric data indicate that the SDQ is a valid instrument to measure disgust for sexual contaminants, with the notion that the relatively low internal consistency may warrant further revision.

In line with the view that experiencing disgust may interfere with sexual functioning and disrupt sexual arousal [6], women reporting relatively high levels of sexual disgust (as indexed by the SDQdisgustingness scale) also displayed relatively low levels of sexual arousal (as indexed by the FSFI-AR and FSFI-LU). This is in line with previous work suggesting that a lack of arousal negatively impacts healthy sexual functioning in women with dyspareunia $[15,16]$. Supporting further the potential relevance of disgust in vaginismus, treatmentseeking women with vaginismus not only showed heightened trait disgust (as indexed by the DS) but also heightened disgust for sexual by-products (as indexed by SDQ-D) compared to healthy control participants. Interestingly, women with dyspareunia did not show similarly enhanced levels of trait disgust and disgust for sexual contaminants. Thus, enhanced disgust seems especially relevant for vaginismus and not a general characteristic of women with sexual dysfunctions. A critical difference between both types of dysfunctions is that women with lifelong vaginismus are characterized by a consistent inability for vaginal penetration, whereas in women with dyspareunia, sexual intercourse is still possible [24]. While pain tends to be observed in both women with vaginismus and dyspareunia upon penetration attempts, disgustrelated defensive reflexes that preclude sexual intercourse may be specific to women with vaginismus.

It should be acknowledged, however, that the SDQ examines disgust toward sexual by-products (e.g., sperm) and does not directly refer to sexual penetration or sexual organs. It remains, therefore, to be established, whether women with vaginismus would also report heightened disgust toward sexual intercourse and/or their partner's penis. Accordingly, it would be interesting to extend the original SDQ by adding items that reflect disgust for specific sexual stimuli (e.g., penis) and/or behaviors (e.g., sexual penetration).

In line with previous findings [9], women with vaginismus did not report lower willingness to handle sexual contaminants compared to the women in the control group (SDQ-W). This casts doubt on the validity of using willingness ratings as an indirect measure of disgust. Indeed, one may question whether willingness ratings are a proper candidate for investigating the potential to evoke disgust responses in sexual dysfunctions. First, it has been argued that reporting imaginary behavioral levels might simply not be a valid method for measuring actual approach-avoidance behavior (e.g., [40]). In addition, the willingness to touch stimuli may also be influenced by factors other than disgust (e.g., culture, religion). To arrive at more final conclusions regarding the validity of the willingness vs. the disgustingness ratings it would be important to test the prognostic value of both dimensions for predicting indi- 
vidual's actual disgust responsivity when confronted with relevant sexual stimuli (e.g., [41,42]).

Pointing to a potential gender difference regarding the relevance of disgust in sexual dysfunction, there was no convincing relationship between disgust for sexual contaminants and sexual arousal in the non-clinical men. Casting further doubt on the relevance of sexual disgust in men, the treatment-seeking participants with erectile disorder also did not show heightened disgust toward sexual contaminants, although it should be acknowledged that these men did show a lowered willingness to handle stimuli that were potentially contaminated by a familiar person (SDQ-W). However, as already mentioned above, factors other than disgust may also be responsible for this reduced willingness to touch "contaminated" stimuli in men. For example, men with erectile disorder may wish to avoid these stimuli because of their negative associations, such as performance anxiety. Future research using implicit measures of disgust such as EMG (e.g., [19]) during behavioral tasks would be helpful to arrive at more solid conclusions regarding the role of heightened sexual disgust and avoidance in erectile disorder.

Several implications for clinical practice can be derived from the present findings. First, the present findings indicate that the role of disgust for sexual contaminants appears most pronounced for women suffering from vaginismus. Hence, treatments on vaginismus may improve by focusing on specific disgust elements. Previous research has already indicated that both fear and disgust may be effectively reduced using exposure in vivo treatment in specific phobias [43]. In a similar vein, exposure has proven effective in reducing fear levels in women with lifelong vaginismus as well [27]. Thus, future research should consider the application of exposure in vivo to objects of sexual disgust (e.g., a woman's vagina or the partner's penis) in women with vaginismus, and investigate whether sexual disgust can thus be reduced, and whether this coincides with a reduction of clinical symptoms $[44,45]$. Second, the current version of the SDQ may be an effective tool to examine whether treatments may successfully reduce sexual disgust in a clinical group with sexual dysfunctions. It would be interesting to see whether residual sexual disgust can predict relapse of clinical symptoms in the long term.

Yet, a number of limitations need to be considered. First, only convergent and construct validity of the SDQ were explored. Future research should test other forms of validity (i.e., predictive validity, divergent validity) as well as test-retest reliability. In particular, research should explore discriminant validity to examine whether the associations between disgust propensity and sexual dysfunctions are not fully attributed to a harm-avoidance conceptualization of vaginismus by measuring fear and pain-avoidance (e.g., [23,50]). Second, the current SDQ covered a limited number of sexual by-products and not specific sex stimuli (e.g., a penis). The current SDQ could be extended to cover a wider range of sexual stimuli and contexts (e.g., using sweat as sexual contaminant or changing the context to one's own home). Germane to this, it would be important to test the relationship between SDQ-scores and actual disgust responsivity when confronted with relevant sexual stimuli (e.g., in the context of behavioral approach tasks [31]). This might help to shed light on the issue of whether SDQ-disgust or SDQ-willingness ratings are the most relevant scales for indexing sexual disgust.

Third, the present findings are correlational in nature. It remains to be established whether enhanced disgust presents a causal factor or a consequence of suffering from a sexual dysfunction. Fourth, sexual relationship status was not assessed for the control participants without sexual problems. Moreover, there may be other marked differences between control and clinical samples that were not controlled for (e.g., number of years in a relationship, cultural and religious backgrounds, moral values). For example, research showed that conservative attitudes were associated with lower thresholds for experiencing disgust for sexual stimuli [46] and African-American individuals have demonstrated elevated levels of disgust propensity compared to white individuals [47]. Future research should take such factors into account. Finally, the current study focused on a limited number of sexual dysfunctions. It would be important to test whether heightened disgust is especially relevant for lifelong vaginismus or might also be involved in other dysfunctions such as hypoactive sexual desire disorder, or problems associated with reduced sexual arousal.

\section{Conclusions}

The current study showed that the SDQ is a helpful instrument to investigate the role of domain-specific disgust in sexual dysfunctions. To increase its sensitivity as a comprehensive index of sexual disgust, it 
might be worthwhile to include additional items. The findings showed that sexual disgust was involved particularly in lifelong vaginismus. Future studies are necessary to delineate further the role of sexual disgust also in other sexual dysfunctions. Improving the understanding of the role of disgust in sexual dysfunctions is not only relevant from a theoretical stance, it may also provide fresh clues to improve currently available treatment options (e.g., [48]) and help lower help-seeking barriers in women with vaginismus (e.g., [49]).

\section{Acknowledgments}

For their help in data acquisition, the authors thank Paul Beker, Ernst Claasen, Marthe Genten, Marieke van Vliet, Maartje van Zandbergen, and Peter Zwaard.

Corresponding Author: Mark van Overveld, $\mathrm{PhD}$, Erasmus University Rotterdam, Rotterdam School of Management, P.O. Box 1738, 3000 DR Rotterdam, the Netherlands. Tel: 010-4081970; Fax: +31-(0)-104089572; E-mail: moverveld@rsm.nl

Conflict of Interest: None.

\section{Statement of Authorship}

\section{Category 1}

(a) Conception and Design

Mark van Overveld; Peter J. de Jong; Madelon L. Peters

(b) Acquisition of Data

Mark van Overveld; Reinhilde Melles; Jacques van Lankveld; Moniek M. ter Kuile

(c) Analysis and Interpretation of Data

Mark van Overveld; Peter J. de Jong; Madelon L. Peters; Jacques van Lankveld; Reinhilde Melles; Moniek M. ter Kuile

\section{Category 2}

(a) Drafting the Article

Mark van Overveld

(b) Revising It for Intellectual Content

Mark van Overveld; Peter J. de Jong; Madelon L. Peters; Jacques van Lankveld; Reinhilde Melles; Moniek M. ter Kuile

\section{Category 3}

(a) Final Approval of the Completed Article

Mark van Overveld; Peter J. de Jong; Madelon L. Peters; Jacques van Lankveld; Reinhilde Melles; Moniek M. ter Kuile

\section{References}

1 Barlow DH. Causes of sexual dysfunction: The role of anxiety and cognitive interference. J Consult Clin Psychol 1986;54: $140-8$.
2 Janssen E, Everaerd W. Determinants of male sexual arousal. Annu Rev Sex Res 1993;4:211-45.

3 van den Hout M, Barlow DH. Attention, arousal and expectancies in anxiety and sexual disorders. J Affect Disord 2000;61:241-56.

4 Payne KA, Binik YM, Amsel R, Khalife S. When sex hurts, anxiety and fear orient attention towards pain. Eur J Pain 2005;9:427-36.

5 Basson R. The recurrent pain and sexual sequelae of provoked vestibulodynia: A perpetuating cycle. J Sex Med 2012;9:207792.

6 de Jong PJ, Peters ML. Sex and the sexual dysfunctions: The role of disgust and contamination sensitivity. In: Olatunji B, McKay D, eds. Disgust and its disorders: Theory, assessment, and treatment. Washington, DC: American Psychological Association; 2009:253-71.

7 Olatunji BO, Sawchuk CN. Disgust: Characteristic features, social manifestations, and clinical implications. J Soc Clin Psychol 2005;27:932-62.

8 Oaten M, Stevenson R, Case T. Disgust as a disease avoidance mechanism: A review and model. Psychol Bull 2009;135:303-21.

9 de Jong PJ, van Overveld M, Weijmar Schultz W, Peters ML, Buwalda F. Disgust and contamination sensitivity in vaginismus and dyspareunia. Arch Sex Behav 2009;38:244-52.

10 Rozin P, Fallon AE, Mandell R. Family resemblance in attitudes to food. Dev Psychobiol 1984;20:309-14.

11 Rozin P, Fallon AE. A perspective on disgust. Psychol Rev 1987;94:23-41.

12 Haidt J, McCauley C, Rozin P. Individual differences in sensitivity to disgust: A scale sampling seven domains of disgust elicitors. Pers Individ Dif 1994;16:701-13.

13 Basson R, Leiblum S, Brotto L, Derogatis L, Fourcroy J, Fugl-Meyer K, Graziottin A, Heiman JR, Laan E, Meston C, Schover L, van Lankveld J, Schultz WW. Revised definitions of women's sexual dysfunction. J Sex Med 2004;1:40-8.

14 Borg C, de Jong PJ, Weijmar Schultz W. Vaginismus and dyspareunia: Automatic vs. deliberate: Disgust responsivity. J Sex Med 2010;7:2149-57.

15 Brauer M, ter Kuile M, Laan E. Effects of appraisal of sexual stimuli on sexual arousal in women with and without superficial dyspareunia. Arch Sex Behav 2009;38:476-85.

16 van Lankveld JJ, Granot M, Weijmar Schultz WC, Binik YM, Wesselmann U, Pukall CF, Bohm-Starke N, Achtrari C. Women's sexual pain disorders. J Sex Med 2010;7:615-31.

17 Reissing ED. Consultation and treatment history and causal attributions in an online sample of women with lifelong and acquired vaginismus. J Sex Med 2012;9:251-8.

18 Huijding J, Borg C, Weijmar-Schultz W, de Jong PJ. Automatic affective appraisal of sexual penetration stimuli in women with vaginismus or dyspareunia. J Sex Med 2010;8:806-13.

19 de Kruijff ME, ter Kuile MM, Weijenborg PT, van Lankveld JJDM. Vaginismus and dyspareunia: Is there a difference in clinical presentation? J Psychosom Obstet Gynaecol 2000;21:149-55.

20 Binik YM. The DSM diagnostic criteria for vaginismus. Arch Sex Behav 2010;39:278-91.

21 Binik YM. The DSM diagnostic criteria for dyspareunia. Arch Sex Behav 2010;39:292-303.

22 Klaassen M, ter Kuile MM. Development and initial validation of the Vaginal Penetration Cognition Questionnaire (VPCQ) in a sample of women with vaginismus and dyspareunia. J Sex Med 2009;6:1617-27.

23 Borg C, Peters ML, Weijmar Schultz WW, de Jong PJ. Vaginismus: Heightened harm avoidance and pain catastrophizing cognitions. J Sex Med 2012;9:558-67.

24 American Psychiatric Association. Diagnostic and statistical manual of mental disorders. 4th edition. Washington, DC: American Psychiatric Association; 2000. 
25 Simons JS, Carey MP. Prevalence of sexual dysfunctions: Results from a decade of research. Arch Sex Behav 2001;30:177-219.

26 Tybur JM, Lieberman D, Griskevicius V. Microbes, mating, and morality: Individual differences in three functional domains of disgust. J Pers Soc Psychol 2009;97:103-22.

27 ter Kuile MM, Bulté I, Weijenborg PTM, Beekman A, Melles $\mathrm{R}$, Onghena P. Therapist-aided exposure for women with lifelong vaginismus: A replicated single-case design. J Consult Clin Psychol 2009;77:149-59.

28 van Overveld WJM, de Jong PJ, Peters ML, Cavanagh K, Davey GCL. Disgust propensity and disgust sensitivity: Separate constructs that are differentially related to specific fears. Pers Individ Dif 2006;41:1241-52.

29 Fergus TA, Valentiner DP. The Disgust Propensity and Sensitivity Scale-Revised: An examination of a reduced-item version. J Anxiety Disord 2009;23:703-10.

30 Olatunji BO, Williams NL, Tolin DF, Abramowitz JS, Sawchuk CN, Lohr JM, Elwood LS. The Disgust Scale: Item analysis, factor structure, and suggestions for refinement. Psychol Assess 2007;19:281-97.

31 van Overveld WJM, de Jong PJ, Peters ML. The Disgust Propensity and Sensitivity Scale-Revised: Its predictive value for avoidance behavior. Pers Individ Dif 2010;49:70611.

32 Rosen R, Brown C, Heiman J, Leiblum S, Meston C, Shabsigh R, Ferguson D, D'Agostino R Jr. The Female Sexual Function Index (FSFI): A multidimensional self-report instrument for the assessment of female sexual function. J Sex Marital Ther 2000;26:191-208.

33 ter Kuile MM, Brauer M, Laan E. The female sexual function index (FSFI) and the Female sexual distress scale (FSDS): Psychometric properties within a Dutch population. J Sex Marital Ther 2006;32:289-304.

34 Rosen RC, Riley A, Wagner G, Osterloh IH, Kirkpatrick J, Mishra A. The international index of erectile function (IIEF): A multidimensional scale for assessment of erectile dysfunction. Urology 1997;49:822-30.

35 Rosen RC, Cappelleri JC, Gendrano N III. The International Index of Erectile Function (IIEF): A state-of-the-art review. Int J Impot Res 2002;14:226-44.

36 Schafer JL, Graham JW. Missing data: Our view of the state of the art. Psychol Methods 2002;7:147-77.

37 Cohen J. Statistical power analysis for the behavioral sciences. 2nd edition. Hillsdale: Lawrence Erlbaum Associates; 1988, $567 \mathrm{pp}$.

$38 \mathrm{Hu} \mathrm{L}$, Bentler PM. Cutoff criteria for fit indexes in covariance structure analysis: Conventional criteria vs. new alternatives. Struct Equ Modeling 1999;6:1-55.

39 Nunnally JC. Psychometric theory. 2nd edition. New York: McGraw-Hill; 1978, 701 pp.

40 Parkinson B, Manstead ASR. Making sense of emotions in stories and social life. Cogn Emot 1993;7:295-323.

41 Borg C, de Jong PJ. Feelings of disgust and disgust-induced avoidance weaken following induced sexual arousal in women. PloS ONE 2012;7:1-8.

42 Stevenson RJ, Case TI, Oaten M. Effect of self-reported sexual arousal on responses to sex-related and non-sex-related disgust cues. Arch Sex Behav 2011;40:79-85.

43 Hirai M, Cochran HM, Meyer JS, Butcher JL, Vernon LL, Meadows EA. Preliminary investigation of the efficacy of disgust exposure techniques in a subclinical population with blood and injection fears. Behav Change 2008;25:129-48.

44 de Jong PJ, van Lankveld J, Elgersma HJ. Refractory cases in the treatment of sexual problems associated with low sexual arousal. In: McKay D, Abramowitz J, Taylor S, eds. Cognitive behavioral therapy for refractory cases: Turning failure into success. Washington, DC: APA; 2010:255-75.
45 de Jong PJ, van Lankveld J, Elgersma HJ, Borg C. Disgust and sexual problems; theoretical conceptualization and case illustrations. Int J Cogn Ther 2010;3:24-41.

46 Borg C, de Jong PJ, Weijmar Schultz WW. Vaginismus and dyspareunia: Relationship with general and sex-related moral standards. J Sex Med 2011;8:223-31.

47 Williams MT, Abramowitz JS, Olatunji BO. The relationship between contamination cognitions, anxiety, and disgust in two ethnic groups. J Behav Ther Exp Psychiatry 2012;1:632-7.

48 Ter Kuile MM, Both S, van Lankveld JJDM. Cognitive behavioural therapy for sexual dysfunctions in women. Psychiatr Clin North Am 2010;33:595-610.

49 Donaldson RL, Meana M. Early dyspareunia experience in young women: Confusion, consequences, and help-seeking barriers. J Sex Med 2011;8:814-23.

50 Reissing ED, Binik YM, Khalife S, Cohen D, Amsel R. Vaginal spasm, pain, and behavior: An empirical investigation of the diagnosis of vaginismus. Arch Sex Behav 2004;33:5-17.

\section{Appendix}

\section{Sexual Disgust Questionnaire (SDQ) SDQ-W}

To what extent are you willing to:

1. Use a towel for your face after it has been used to wipe off sperm/vaginal fluids from yourself after sexual intercourse and smells accordingly.

2. Use a towel for your face after it has been used to wipe off sperm from your partner after sexual intercourse and smells accordingly.

3. Lie beneath bedclothes in a hotel, that look unwashed and below which previous guests may have had sexual intercourse.

4. Lie beneath bedclothes below which you have masturbated the day before and which show obvious smudges.

5. Use a towel for your face that has been thoroughly cleaned after it has been used following sexual intercourse to wipe off sperm/ vaginal fluids of an unknown person (e.g., a towel in a hotel).

6. Touch a soiled, unwashed towel, that is possibly used to wipe off sperm/vaginal fluid of an unknown person after sexual intercourse (e.g., a towel in a hotel).

Certainly Probably Maybe willing, Probably Certainly not willing not willing maybe not willing willing

\begin{tabular}{lllllllll}
\hline 0 & 1 & 2 & 3 & 4 & 5 & 6 & 7 & 8
\end{tabular}

\section{SDQ-D}

To what extent are you disgusted when you would:

7. Use a towel for your face after it has been used to wipe off vaginal fluids from yourself after sexual intercourse and smells accordingly.

8. Use a towel for your face after it has been used to wipe off sperm from your partner after sexual intercourse and smells accordingly.

9. To lie beneath bedclothes in a hotel, that look unwashed and below which previous guests may have had sexual intercourse.

10. Lie beneath bedclothes below which you have masturbated the day before and which show obvious smudges.

11. Use a towel for your face that has been thoroughly cleaned after it has been used following sexual intercourse to wipe off sperm/ vaginal fluids of an unknown person (e.g., a towel in a hotel).

12. Touch a soiled, unwashed towel, that is possibly used to wipe off sperm/vaginal fluid of an unknown person after sexual intercourse (e.g., a towel in a hotel).

\begin{tabular}{llllllll}
$\begin{array}{l}\text { No disgust } \\
\text { at all }\end{array}$ & Some disgust & Disgust & $\begin{array}{l}\text { Strong } \\
\text { disgust }\end{array}$ & $\begin{array}{l}\text { Extreme } \\
\text { disgust }\end{array}$ \\
\hline 0 & 1 & 2 & 3 & 4 & 5 & 6 & 7
\end{tabular}

